\title{
Mental Actions and Mental Agency
}

\author{
Anika Fiebich ${ }^{1} \cdot$ John Michael $^{2}$
}

(C) Springer Science+Business Media Dordrecht 2015

\section{Introduction: Actions and Agency}

This special issue discusses various aspects of mental actions and mental agency. Mental actions and mental agency are specific subcategories of actions and agency, respectively. The challenges of elucidating what 'actions' are in contrast to other bodily movements, and what role 'agency' plays in performing such actions, have elicited intensive discussion within the framework of Action Theory. Thus, before discussing the peculiarities of mental actions and mental agency, and the specific contributions of our authors to these issues, we would like to give a brief introduction to some of the core insights from classic Action Theory.

According to a prominent view in Action Theory, actions - in contrast to other bodily movements, like reflexes - are caused by some an agent's beliefs, desires and/or other mental states. Donald Davidson ([1963] 2001), for example, argues that an individual's reasons to act function as causes of his or her action. According to Davidson, an individual acts for what she calls a 'primary reason' when the individual "can be characterized as (a) having some sort of pro attitude towards actions of a certain kind and (b) believing (or knowing, perceiving, noticing, remembering) that this action is of that kind." (p. 3-4). For example, when an individual feels hungry (pro attitude) and believes there is something to eat in the fridge, this belief-desire pair causes the individual to walk to the fridge (and eat something). Proponents of a teleological approach to action, in contrast, argue that actions are not caused by mental events but need to be explained by the teleological dimension of the action in question, i.e. by the aims and goals that an agent pursues when executing an action. Alfred Mele (2000), for example, argues for a teleological account of action and against a causal account of action, illustrating by means of a series of examples that an agent's bodily movements may be consistent with but are still not caused by the agent's beliefs and desires. Others

Anika Fiebich

anifiebich@gmail.com

John Michael

MichaelJ@ceu.edu

1 Duisburg-Essen University, Essen, Germany

2 CEU Budapest, Budapest, Hungary 
have defended a causal approach to action but argued that actions are caused by intentions, which are irreducible to belief-desire pairs (e.g., Bratman 1987). Margaret Anscombe ([1957] 1972) distinguishes between intentionally performed actions, actions that are guided by an individual's future intention to act, and actions that have been performed with the intention to achieve a specific purpose. Focusing on the two former kinds, a number of philosophers have proposed a two-fold account of intention; for example, Michael Bratman's concept of 'present-direction intentions' versus 'future-directed intentions', Alfred Mele's (1992) concept of 'proximal intentions' versus 'distal intentions', John Searle's (1983) concept of 'intentions-in-action' and 'prior intentions', or Myles Brand's (1984) concept of 'prospective intentions' versus 'immediate intentions'. Some authors have argued that these different kinds of intention are causally connected with each other. For example, on Searle's (1983) account, prior intentions cause the action, which is composed of an intentional component (intentionin-action) and a physical component (bodily movement) whereby the intentional component causes the physical one. Élisabeth Pacherie $(2006,2008)$ provides a three-fold account of intention, distinguishing among 'distal intentions', 'proximal intentions' and 'motor intentions'. On this account, motor intentions are based on sensori-motor information, and are caused by proximal intentions, which in turn may be caused by distal intentions.

In this context, there has also been much controversial discussion about the role of individual intentions within collective actions, ranging from the proposal that collective actions depend upon so-called 'we-intentions' - i.e. intentional attitudes which are entertained in an irreducibly collective mode by individuals within collective actions (Searle 1990), to the proposal that shared intentions are reducible to the interrelation of personal contributory intentions of individual group members (Bratman 1993), and to the proposal that collective actions are brought about by the intentions of 'plural subjects', and are not reducible to individuals' intentions (Gilbert 2009).

Some accounts of 'intention' clearly point to the role of consciousness and deliberative control in actions. Anscombe ([1957] 1972, p. 12 ff.), for example, argues that an individual acts on an intention when the 'why question' has application ('Why did you do X'?). On her account, this question can be refused when it is legitimate to answer:

(i) "I was not aware I was doing that" (i.e., the individual is not aware of performing an action under a specific description; e.g. he or she is aware of sawing a plank but not of sawing one of Smith' planks);

(ii) "It was involuntary" (i.e., bodily movements under a pure physical description; e.g., reflexive kicks by the knee); or

(iii) "I knew I was doing that, but because I observed it" (e.g., the individual notices that her movements influence the traffic lights as she is crossing a road).

Awareness and deliberative control are features that have been discussed intensively with respect to the dimension of agency in Action Theory. Agency refers to an individual causing or generating an action voluntarily. Within this debate, the experience of one's own agency has been referred to as the 'sense of agency.' As pointed out by Shaun Gallagher (2012), an individual experiences a sense of agency (SA) when he or she causes or generates an action voluntarily, but lacks a SA in cases of involuntary bodily movements. Nevertheless, in the latter sort of case, the individual typically has a 
sense of ownership (SO), which is the sense of being the owner of the body that is moving. Various aspects of the SA have been discussed in the literature; e.g., the reflectiveness and pre-reflectiveness of the SA and its relation to the self (Gallagher 2000, 2012), feeling-based versus judgment-based accounts of the SA (Synofzik et al. 2008), phenomenological dimensions of SA and SO, such as an experience of intentional causation, the sense of initiation and the sense of control (Pacherie 2007), the sense of group agency in joint action (Dewey et al. 2014) as well as the neuronal foundations of SA (Haggard 2005; Tsakiris and Haggard 2005).

\section{Mental Actions and Mental Agency: Content of the Special Issue}

Traditionally, action theorists have focused primarily on 'overt actions' that involve bodily movements. In recent years, however, mental actions have gained more and more attention. 'Mental actions' may not be expressed by bodily movements at all. Rather, they occur in the head of the agent, e.g., when solving a chess problem or thinking about whether to accept a job offer (see Mele 1997 for a discussion). Much of the discussion of mental actions has transpired against the background of causal theories of action. For example, in approaching the question as to what mental activities should be counted as actions, Galen Strawson (2003) denies the status of actions to many types of mental activity on the grounds that they lack the appropriate causal history. Specifically, Strawson submits that most mental activities, such as most instances of thinking, reasoning, and deciding, occur spontaneously rather than having been caused by mental states. While we can sometimes intentionally direct our mental activity, as when we decide to focus on a problem or attempt to remember some fact, the actual solution of the problem, or the occurrence of the recalled fact, just happens to us, with our role being essentially passive. In Strawson's terms, mental action is usually just prefatory in most mental activities: 'It is essentially-merely-catalytic' (2003, 231).

In fact, two arguments have motivated the view that most mental activity must be passive, on pain of conceptual confusion. The first argument arises out of a concern Gilbert Ryle formulated about the notion that volition is a mental operation causing voluntary movement. As Ryle sees it, this notion would require volition itself to have been caused by some prior volition ad infinitum (p. 67). As applied to the mental activity of heeding, the Rylean regress runs as follows: “... far from heeding being a sort of inspecting or monitoring, inspecting and monitoring are themselves special exercises of heed (. . . ) Doing something with heed does not consist in coupling an executive performance with a piece of theorising, investigating, scrutinizing or 'cognising'; or else doing anything with heed would involve doing an infinite number of things with heed" (Ryle 1949, 137).

The second argument amounts to a challenge to articulate how one could entertain any thought content before one had already isolated the relevant content: if I want to think about a dog and a shark playing fetch together, isn't it necessary that I already entertain this thought content in order to decide voluntarily to think about it (Strawson 2003; Ruben 1995)?

In contrast to these skeptical views of mental action, some authors have focused on the role of intentional action in guiding and controlling mental activity rather than in 
initiating mental activity. Thus, Joëlle Proust (2001) and Andrei Buckareff (2005) have argued that many mental activities do not only involve intentions at the (prefatory or catalytic) stage, but continuously. In articulating this idea, they have identified trying as a crucial criterion for mental action. As Proust puts it: "To determine whether some piece of behavior qualifies as an action [...] just consider whether it can meaningfully be tried" $(2001,108)$. In line with this, Christopher Peacocke (2007) has argued that for there to be a mental action, a mental event either is or constitutively involves a trying, which needs to be sharply distinguished from prior intentions. Brian O'Shaughnessy (2000), in contrast, has argued that the criterion of trying may play a role in any action that is expressed bodily but that this is not necessarily the case for mental actions.

O'Shaughnessy is particularly interested in the interrelation between mental action and consciousness. He describes thinking as an active process that is essentially linked to consciousness, wherein mental actions play a central role. Consciousness, in turn, may play a central role in having a sense of one's own mental agency, i.e. being the agent of one's own mental actions. Peacocke (2009), for example, argues that the awareness of one's own mental actions such as 'judging that p' draws on taking at face value an awareness with the content that oneself is the agent who is judging that $p$. Fabian Dorsch (2009), in contrast, distinguishes between mental actions (such as judging) that we experience as epistemically motivated ('mediated' agency) and mental actions (such as remembering) that we experience as practically motivated ('straightforward' agency) (see Soteriou 2009 for an overview).

Defending an evaluativist rather than attributivist view, Proust (2014a) defines 'metacognition' as experience-based epistemic self-evaluation, which relies on affective and doxastic types of information and does not necessarily require the formation of meta-representations. Moreover, Proust highlights that metacognition is essentially linked to mental agency, arguing that being sensitive to the adequacy of one's own mental actions by means of meta-cognitive self-probing and post-evaluation allows for knowledge of one's own mental actions (see Proust 2014b; Michaelian 2015 for a review). On her account, mental agency is disturbed in the experience of thought insertion where subjects with schizophrenia have a preserved 'sense of ownership' but an impaired 'sense of agency' for their own mental action, believing that it is not they themselves but others who are responsible for the initiation of the thoughts they experience (see also Peacocke 2007; Gallagher, this volume, for similar discussions).

Most discussions so far have focused on establishing mental action and mental agency as legitimate and interesting categories, and addressing conceptual issues that they raise. Building upon this foundational work, there are various open questions to be explored in further articulating and making use of these concepts. For example, should the intentions underlying mental actions be analyzed in terms of the same hierarchical structure as many researchers have proposed in the case of bodily actions (e.g. Pacherie's (2006) taxonomy of distal, proximal, and motor intentions, or Searle's (1983) distinction between prior intentions and intentions in action)? If so, how should such a framework be applied in the case of mental actions, and what basis would it provide for characterizing action monitoring and/or action control in the case of mental actions? What new impulses does an enriched understanding of mental action generate for the ongoing free will debate?

Turning to the concept of mental agency, it is an interesting challenge to work towards an account of the cognitive prerequisites for a capacity to perform mental 
actions and to have a sense of doing so. Does mental agency and/or a sense of mental agency, for example, presuppose a capacity for metacognition? If so, what conception of metacognition is best suited to account for this? And what role do mindreading and introspection play in that conception? Is the ability to distinguish between self and other necessarily required for having a sense of mental agency? In answering these questions, does 'mental agency' need to be understood as an all-or-nothing phenomenon, or is it appropriate to assume that mental agency comes in degrees? If the latter is the case, how should the most basic forms of mental agency be characterized? What functions of mental agency may be present in non-human animals or in preverbal children, and which ones are present only in the cognitive systems of human adults? What insights may we gain from findings pertaining to the dysfunctions of mental agency in psychopathological cases such as schizophrenia for understanding how mental agency typically works in adult humans? The present special issue aims to bring together attempts to make use of the concepts of mental action and mental agency as theoretical tools, e.g., in conceptualizing neglected types or aspects of intentional action and action preparation, in theorizing about empirical findings, in generating new questions for theoretical and empirical research. Methodologically, we have separated the contributions to this volume into those focusing on 'mental actions' with respect to primitive mental actions (section 2.1.1), evolutionary constraints and evolutionary roots (section 2.1.2), and deliberative control and willpower (section 2.1.3), and those focusing on 'mental agency' with respect to self-regulation and mindwandering (2.2.1), epistemic dimensions of mental agency (2.2.2), and mental agency and ownership: illusions and delusions (2.2.3).

\subsection{Mental Actions}

\subsubsection{Primitive Mental Actions}

Alessandro Salice provides a critical analysis of Searle's (1990) conception of collective intentions-in-action. In individual actions, Searle (1983) distinguishes between (i) prior intentions that are formed prior to the action onset and initiate the causal chain of an action, and (ii) intentions-in-action that control and cause the bodily movements whilst executing an action. This distinction can also be made with respect to collective actions. According to Searle, collective intentions are irreducible to I-intentions because when holding a we-intention, individuals intend to cooperate with one another to reach a shared goal. For example, an individual intends to reach a collective goal together with another individual by means of his or her own contribution ("We intend to make Sauce Béarnaise by means of me stirring"). However, as pointed out by Salice, the complexity of collective intentions-in-action does not make them different in kind from instrumental singular intentions: both are complex only in the sense that they have a means-end structure and this complexity can be cashed out conceptually by arguing that it is located within the content of the intention. Moreover, in collective intentions-in-action, only the own contribution of the individual who has that intention figures in the content, but not the contribution of the other individual(s). Hence, contrary to what Searle has proposed, Salice comes to the conclusion that "there are no primitive we-intentions". 


\subsubsection{Evolutionary Constraints and Evolutionary Roots}

In order to explore the kind of mental event that triggers mental actions, - a notoriously difficult issue -, Joelle Proust investigates the evolutionary constraints that shape action. On her view, three types of trade-off between timing and cognitive resources, on the one hand, and stakes, on the other, have shaped three action systems. (i) Impulsive actions have the function of swiftly responding to environmental or cognitive demands. Taking shelter from a rainstorm and trying to retrieve a proper name in conversation are cases in point. (ii) Routine actions have the function of responding to recurrent needs or wants at a low cognitive cost. Examples of routine action are the daily preparation of breakfast, or looking up a number in a phone book. (iii) Strategic actions have the function of identifying and responding to new needs at different points in time in a changing world, based on one's beliefs and preferences. For example, agents can plan their vacations by taking various constraints into account and organizing subgoals hierarchically, or they can plan to acquire new cognitive competences over the next months or years. Granting this functional tripartition, Proust suggests, the mental states triggering actions, whether bodily or mental, also need to differ in their informational basis. In the third case, agents form propositional prior intentions and plans, which can combine beliefs and adjust over time to variations of predicted outcome. In the first two cases, however, agents act on predictive affordance-sensings. These mental states are evaluative rather than propositional; they associate a given valence, intensity, and disposition to act with a situation or an opportunity. Of particular interest for mental action is agents' ability to impulsively respond to cognitive affordances, thanks to specialized noetic feelings.

The evolutionary perspective championed by Proust also points toward the possibility that non-human animals may also exhibit some forms of mental agency. In this vein, Angelica Kaufmann turns her attention to the interesting question as to what forms of mental agency are present in non-human creatures. Examining chimpanzee hunting as a case study, she argues that there are good grounds for believing that chimpanzee behavior is guided by distal intentions. The problem which she then identifies is to make sense of distal intentions in non-linguistic creatures. Drawing upon the Davidsonian view that concepts are only present in linguistic creatures, Kaufmann concludes that the distal intentions which enable action planning and guide behavior in chimpanzees (and likely also in other non-human creatures) must be nonconceptual.

\subsubsection{Deliberative Control and Willpower}

As we have already seen, consideration of the notion of mental agency against the background of causal theories of action can lead to vexing conceptual puzzles, such as Ryle's infinite regress objection. But some of the contributions in this volume offer the promise of getting around these issues either with novel neuroscientific models or with careful evaluation of thought experiments.

The view, espoused by a number of action theorists, that intentions in the mind of a single individual precede and cause the individual's actions (e.g., Searle 1983; Pacherie 2008), is widely considered to be supported by neuroscientific research. For example, Libet et al. (1983) found that the cortical 'readiness potential' preceding voluntary 
movements also precedes the conscious decision to act by $300 \mathrm{~ms}$ or more. Schurger and Uithol however provide an in-depth analysis of recent findings from the neuroscience of movement initiation that challenge this view (e.g., Selen et al. 2012; Schurger et al. 2012). These findings suggest that there is no neural event that (i) causes an action, and (ii) would qualify, according to action theorists, as an 'intention to act'. Rather, decision-making processes emerge from dynamically interacting control processes in the brain, which are tightly coupled to feedback from the body. This allows for a novel interpretation of classic experimental findings. This, Schurger and Uithol introduce what they call the brain+body decision model, which predicts that the neuronal activity found by Libet et al. is not a consequence of an agent's decision to act, but rather is antecedent to the agent's decision. Using a dynamical systems account, they argue that the 'decision', or commitment, to initiate movement emerges very late in time relative to movement onset. As with the onset of an avalanche, random subthreshold activity combined with positive feedback contribute to determining the precise onset time. Thus, according to this account, actions emerge from a causal web in the brain, without necessarily a specific antecedent intention.

Drawing upon wholly different methods, Till Vierkant's project is to challenge the view that instances in which agents exercise willpower to withstand temptation are fundamentally different from instances in which they disable agency for the period in which they might be tempted (i.e. in which they 'tie themselves to the mast,' as Odysseus did to protect himself from the temptation of the Sirens' song). According to this intuitive view, willpower is about defeating temptation head on as an agent, whereas tying oneself to the mast strategies simply make it impossible to give in to temptation. Vierkant, in contrast, argues that there is no qualitative difference between these types of case: According to Vierkant this is, because on a closer look it turns out that all cases that are considered true willpower also employ a form of tying to the mast. The ties employed in these cases are normally easier to break and require higher maintenance, but they are nevertheless ties and operate in the same way as the ties in the traditional tying to the mast scenarios. In other words, will power is always about taking part of the control effort away from the agent and to load it on to the environment.

\subsection{Mental Agency}

\subsubsection{Self-Regulation and Mindwandering}

Fabian Dorsch uses the notion of mental agency to draw a distinction between mindwandering and focused daydreaming. The latter, as he understands it, is a kind of mental project with the purpose of voluntarily producing specific mental representations. The purposiveness of focused daydreams provides them with unity and a narrative structure. For example, daydreaming about climbing Mount Everest will tend to be constrained insofar as it will tend to incorporate only features that are relevant to the endeavor of climbing Everest: one will think about preparations that would be appropriate to make, the Himalayan landscape en route to the summit, the conditions at the summit, people one would likely be with, etc. Mind-wandering, on the other hand, is not similarly constrained by a central theme or purpose, so it does not have the unity or narrative structure of focused daydreams. Instead, thoughts follow upon each other 
simply because they are associatively linked. As a result, while in the case of focused daydreams we can make sense of the sequence of episodes as a whole (unity), in terms of their contents being linked to a common representational purpose, in the case of mindwandering we can at best make sense of steps between specific pairs of episodes, in terms of their associative links, many (but not all) of which are due to their contents.

Leon De Bruin, Fleur Jongepier, and Derek Strijbos take up the challenge of articulating the sense in which we have first-person authority over our own mental states. They take their starting point in Moran's analysis, who argues that by making avowals, we can commit ourselves to thinking (as well as acting) in accordance with those avowals. They point out, however, that such an analysis cannot properly accommodate the phenomenon that sometimes our dispositional beliefs (as well as our actions) depart from our avowals. Drawing on McGeer's analysis of self-regulation, they argue that commitments arising through avowals normally leave further work to be done for an agent to be considered an authoritative self-ascriber, including the undertaking of bodily actions and the strategic influencing of the agent's physical environment and the social interactions he/she is engaged in. Thus, in order to account for firstperson authority, we need to go beyond the 'pure' deliberative form of mental agency advocated by Moran, and instead adopt a notion of mental agency as an (often) indirect, unconscious and inter-personal process of self-regulation.

\subsubsection{Epistemic Dimensions of Mental Agency}

Cristina Borgoni argues for epistemic acrasia being a psychologically possible phenomenon. There are two conditions that are together sufficient for there to be epistemic akrasia: (i) knowingly believing that $\mathrm{p}$ though judging that it is epistemically wrong to believe so; and (ii) displaying a failure of mental agency by having these mental states. Borgoni discusses two types of epistemic acrasia. First, she discusses acratic cases in which an individual has a particular belief at the same time that he or she accepts undercutting evidence against that belief. Borgoni argues that such cases are possible since although beliefs ought to respond to counter evidences, there may be cases in which beliefs simply do not respond correctly to such evidence or even become insensitive towards it. Second, she discusses akratic cases in which an individual has a particular belief at the same time that he or she accepts rebutting evidence against that belief. Borgoni argues for the possiblity of such cases by constructing a case based on subjects who suffer from phantom limb syndrome. In the proposed case, the subjects know that they do not have a left hand but still have the recalcitrant belief that they have a left hand. Borgoni highlights that even though such subjects have phenomenal consciousness of that belief, they lack consciousness of that belief via their own rational powers (so-called rational-access consciousness). Finally, Borgoni argues that when generating a reason that a belief is epistemically defective in critical reasoning processes, such reason typically leads to modifying or withdrawing the belief. This is not the case in epistemic akrasia. According to Borgoni, the failure to implement one's own reasons is a failure of mental agency.

In his contribution, Andras Szigeti considers another epistemic dimension of mental agency, namely the question whether a particular type of mental agency (epistemic agency) should be ascribed to groups. Epistemic actions, as Szigeti understands them, are actions which aim to change the properties of one's own epistemic states, and 
epistemic agency denotes the capacity to bring about such changes. He argues that the notion of collective epistemic agency is incoherent because reasons-for-groups are ipso facto reasons-for- individual(s). Instead of talking about reasons-for-groups, we should therefore distinguish between self-regarding reasons and group-regarding reasons, both of which are reasons-for-individuals. As an alternative to the notion of collective epistemic agency, he proposes that group-level irrationality can arise because even rational individuals can fail to reason about how their attitudes will combine with those of others.

\subsubsection{Mental Agency and Ownership: Illusions and Delusions}

Shaun Gallagher challenges two arguments that have been raised recently to account for thought insertion in schizophrenia as primarily a problem with the sense of ownership rather than with the sense of agency. First, Bortolotti and Broome (2009) have argued that schizophrenic subjects reflectively disown the inserted thought, because they are not capable of providing reasons for thinking it. Rather than endorsing a spatial characterization of ownership, Bortolotti and Broome embrace a conception that is 'more demanding' insofar as it requires the subject to acknowledge the thought consciously as his or her own. Gallagher contends that a reflectively uttered statement by a schizophrenic subject not to be the owner of a thought does not signify a lack of sense of ownership on a pre-reflective level. Rather, what is missing when subjects utter such statements is the feeling of being the generator of the thought in question. Second, Billon (2013) also endorses a more demanding concept and like Bortolotti and Broome, argues that thought insertion involves problems with the reflective attribution of ownership. Billon argues that inserted thoughts lack phenomenality and therefore subjectivity (a quality of ownership the subject can attribute to himself). This would mean that there is nothing it feels like to have an inserted thought; it doesn't feel alien, because it doesn't feel like anything. Gallagher suggests that to the extent that the subject of inserted thoughts comes upon the thought in question reflectively, it must seem to be a thought that he or she did not generate. In that case, it is still the sense of agency that is problematic. Gallagher concludes that these authors endorse a concept of the reflective sense of ownership that ultimately depends on the pre-reflective sense of agency. Hence the traditional view that schizophrenic thought insertion is primarily a problem with the sense of agency can be retained.

In contrast to the more phenomenologically-based approach of Gallagher, Adrian Alsmith defends the idea of a cognitive approach to the sense of ownership. Such a cognitive account proposes that experiencing something as one's own requires thinking about something as one's one. Alsmith discusses a variety of situations in which individuals might experience a sense of ownership according to both phenomenal and cognitive accounts; e.g., experiences in which I compare my experience to someone else's, when evaluating an experience as being a certain way or simply remembering an experience. In contrast, only phenomenal accounts propose that canonically thought-independent phenomena such as merely seeing a drop of blood on a white rose or feeling the pressure of one's own fingers in the palm when clenching the hand into a fist do not amount to the class of cases in which individuals experience a sense of ownership. Alsmith illustrates that the cognitive account can explain the reported experienced of ownership for an invisible hand. The spontaneous imagination 
involved here is a form of mental activity whose effect on an individual's experience often remains unnoticed to the individual in question.

\section{Outlook}

This volume comprises a series of innovative and original articles that shed new light on an emerging topic in Action Theory: mental actions and mental agency. Of course, the aspects discussed here do not cover the whole range of issues raised by this topic. For example, it may be fruitful to explore the question as to what types of mental action might be more basic than others; are there basic mental actions in the sense that one cannot perform them by performing other mental actions, but one can perform other mental actions by performing them? Moreover, while some of the papers in this volume have addressed the phylogenetic roots of mental actions and mental agency, there are also many questions to be asked about the ontogenetic roots of mental actions and mental agency. For example, what are the cognitive prerequisites for the development of a sense of mental agency; an ability to distinguish between self and other? A conceptual understanding of intentions and/or other mental states? How does the development of a sense of mental agency relate to the development of mindreading or of introspection? Moreover, other epistemic dimensions and other kind of illusions and delusions than those that have been discussed here may be interesting to address in future research. For example, previous research suggesting that mental illnesses such as depression (Kavanagh 1992) and phobic disorders (Williams 1995) may have a negative impact upon the sense of self-efficacy provide good reason to suspect that the sense of mental agency may also be effected in individuals suffering from these conditions, and that this may interfere with these individuals' ability to remain committed to beneficial treatment programs.

Though the limited space of such a special issue inevitably necessitates difficult decisions about the scope of topics and perspectives to include, we hope that the papers in this issue will inspire and enrich further theoretical discussion and empirical investigation.

\section{References}

Anscombe, M. [1957] 1972. Intention (2nd ed.). Oxford: Basil Blackwell.

Billon, A. 2013. Does consciousness entail subjectivity? The puzzle of thought insertion. Philosophical Psychology 26(2): 291-314.

Bortolotti, L., and M. Broome. 2009. A role for ownership and authorship in the analysis of thought insertion. Phenomenology and the Cognitive Sciences 8(2): 205-222.

Brand, M. 1984. Intending and acting. Cambridge: MIT Press.

Bratman, M. 1987. Intentions, plans, and practical reasons. Cambridge: Harvard University Press.

Bratman, M. 1993. Shared intention. Ethics 104(1): 97-113.

Buckareff, A. 2005. How (not) to think about mental action. Philosophical Explorations 8(1): 83-89.

Davidson, D. [1963] 2001. Essay 1. Actions, reasons, and causes. In D. Davidson (Ed.), Essays on actions and events (2nd ed.) (pp. 3-19). Oxford: University Press.

Dewey, J., E. Pacherie, and G. Knoblich. 2014. The phenomenology of controlling a moving object with another person. Cognition 132(3): 383-397. 
Dorsch, F. 2009. Judging and the scope of agency. In Mental actions, ed. L. O'Brian and M. Soteriou, 38-71. Oxford: Oxford University Press.

Gallagher, S. 2000. Philosophical conceptions of the self: Implications for cognitive science. Trends in Cognitive Science 4(1): 14-21.

Gallagher, S. 2012. Multiple aspects in the sense of agency. New Ideas in Psychology 30: 15-31.

Gilbert, M. 2009. Shared intention and personal intentions. Philosophical Studies 144: 167-187.

Haggard, P. 2005. Conscious intention and motor cognition. Trends in Cognitive Sciences 9(6), 290-295.

Kavanagh, D. 1992. Self-efficacy and depression. Self-efficacy: Thought control of action, 177-193.

Libet, B., C. Gleason, E. Wright, and D. Pearl. 1983. Time of conscious intention to act in relation to onset of cerebral activity (readiness-potential): The unconscious initiation of a freely voluntary act. Brain 106(3): 623-642.

Mele, A.R. 1992. Springs of action. Oxford: University Press.

Mele, A.R. 1997. Agency and mental action. Philosophical Perspectives 11: 231-249.

Mele, A.R. 2000. Goal-directed action: Teleological explanations, causal theories, and deviance. Noûs 34(s14): 279-300.

Michaelian, K. 2015. Book review. The philosophy of metacognition: Mental agency and self-awareness by Joelle Proust. Analysis Reviews, 1-3.

O'Shaughnessy, B. 2000. Consciousness and the world. Oxford: Oxford University Press.

Pacherie, E. 2006. Towards a dynamic theory of intention. In Does consciousness cause behavior? An investigation of the nature of volition, ed. S. Pockett, W.P. Banks, and S. Gallagher, 145-167. Cambridge: MIT Press.

Pacherie, E. 2007. The sense of control and the sense of agency. Psyche, 13(1).

Pacherie, E. 2008. The phenomenology of action: a conceptual framework. Cognition 107: 179-217.

Peacocke, C. 2007. Mental action and self-awareness. In Contemporary debates in the philosophy of mind, ed. J. Cohen and B. McLaughlin. Oxford: Blackwell.

Peacocke, C. 2009. Mental actions and self-awareness (II): Epistemology. In Mental actions, ed. L. O’Brian and M. Soteriou, 192-214. Oxford: Oxford University Press.

Proust, J. 2001. A plea for mental acts. Synthese 129: 105-128.

Proust, J. 2014a. The philosophy of metacognition: Mental agency and self-awareness. Oxford: Oxford University Press.

Proust, J. 2014b. Précis of the philosophy of metacognition. Philosophy and Phenomenological Research 89(3): 703-709.

Ruben, D. 1995. Mental overpopulation and the problem of action. Journal of Philosophical Research 20: 511-524.

Ryle, G. [1984].1949. The concept of mind. London: Hutchinson.

Schurger, A., J. Sitt, and S. Dehaene. 2012. An accumulator model for spontaneous neural activity prior to self-initiated movement. Proceedings of the National Academy of Sciences of the United States of America 109(42): E2904-E2913.

Searle, J. 1983. Intentionality. An essay in the philosophy of mind. Cambridge: University Press.

Searle, J. 1990. Collective intentions and actions. In Intentions in communication, ed. P. Cohen, J. Morgan, and M. Pollack, 401-415. Cambridge: MIT Press.

Selen, L., M. Shadlen, and D. Wolpert. 2012. Deliberation in the motor system: Reflex gains track evolving evidence leading to a decision. Journal of Neuroscience 32(7): 2276-2286.

Soteriou, M. 2009. Introduction. In Mental actions, ed. L. O’Brian and M. Soteriou, 1-16. Oxford: Oxford University Press.

Strawson, G. 2003. Mental ballistics or the involuntariness of spontaneity. Proceedings of the Aristotelian Society 76: 227-256.

Synofzik, M., Vosgerau, G., \& Newen, A. 2008. I move, therefore I am: A new theoretical framework to investigate agency and ownership. Consciousness \& Cognition 17(2), 411-424.

Tsakiris, M., and P. Haggard. 2005. Experimenting with the acting self. Cognitive Neuropsychology 22(3/4): $387-407$.

Williams, S. 1995. Self-efficacy, anxiety, and phobic disorders. In Self-efficacy, adaptation, and adjustment. Springer US: $69-107$. 